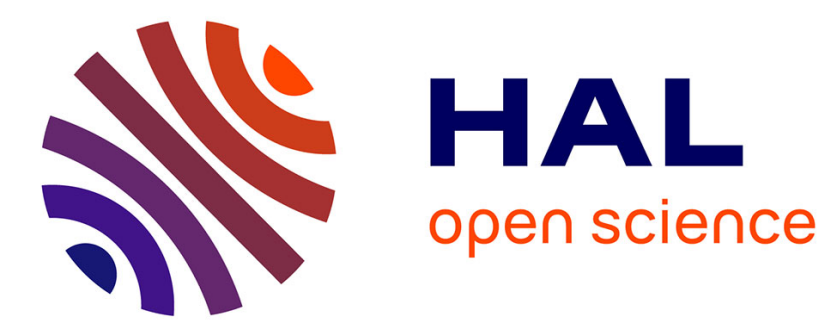

\title{
Cylindrical periodic structures of metallic wires
}

Halim Boutayeb, Kouroch Mahdjoubi

\section{- To cite this version:}

Halim Boutayeb, Kouroch Mahdjoubi. Cylindrical periodic structures of metallic wires. Nov 2003, pp. 319-322, 10.1109/ISAPE.2003.1276692 . hal-00133709

\section{HAL Id: hal-00133709 \\ https://hal.science/hal-00133709}

Submitted on 27 Feb 2007

HAL is a multi-disciplinary open access archive for the deposit and dissemination of scientific research documents, whether they are published or not. The documents may come from teaching and research institutions in France or abroad, or from public or private research centers.
L'archive ouverte pluridisciplinaire HAL, est destinée au dépôt et à la diffusion de documents scientifiques de niveau recherche, publiés ou non, émanant des établissements d'enseignement et de recherche français ou étrangers, des laboratoires publics ou privés. 


\title{
Cylindrical Periodic Structures of Metallic wires
}

\author{
Halim Boutayeb and Kouroch Mahdjoubi \\ IETR - Institut d'Electronique et de Télécommunication de Rennes, Université de Rennes 1, Bât. 11 C, Campus \\ de Beaulieu, 35042 Rennes - France. Halim.Boutayeb@univ-rennes1.fr
}

\begin{abstract}
First, we calculate the total field for an outgoing or an incoming TM cylindrical incident wave illuminating a cylindrical periodic structure of metallic wires. Then, we give analytical formulas to extract the characteristics (reflection and transmission) of the cylindrical periodic structure. To finish, we extend the study to infinite radius periodic structure by given an approximation of the dispersion diagram.
\end{abstract}

\section{I- Introduction}

Cylindrical periodic structures are not often used in antenna devices. Before associating this type of structures with an antenna it is important to understand there characteristics.

In part II, we calculate the total field due a cylindrical periodic structure of metallic wires illuminated by an outgoing cylindrical wave or an incoming cylindrical wave, outside and inside the cavity. Unlike in the plane case, in the cylindrical structure we have not access directly to the characteristics of the cylindrical surface because of the multiples reflections between the center and the surface. In part III, we show how to extract the reflection and transmission characteristics of a single cylindrical surface by the knowledge of the preceding results. In part IV, the multiple layer periodic structure characteristics are deduced from one surface characteristics.

\section{II- Calculation of the total field}

The cylindrical periodic structure of infinite long metallic wires (figures 1 ) have the following parameters : $\mathbf{C}$ is the radius of the cylinder, $\mathbf{a}$ is the diameter of the wires, $\mathbf{P}_{\theta}$ is the angular period, $\mathbf{P}_{\mathbf{t}}$ is the transversal period $\left(\mathrm{P}_{\mathrm{t}}=\mathrm{P}_{\theta} * \mathrm{C}\right)$ and $\mathbf{N}=360 / \mathrm{P}_{\theta}$ is the number of wires.

In figure $1 a$ the structure is illuminated by a TM outgoing cylindrical wave and in figure $1 b$ we consider a TM incoming cylindrical incident wave. For these two cases (case $1 a$ and case $1 b$ ) we will calculate the total Electric field inside and outside the cylindrical cavity.

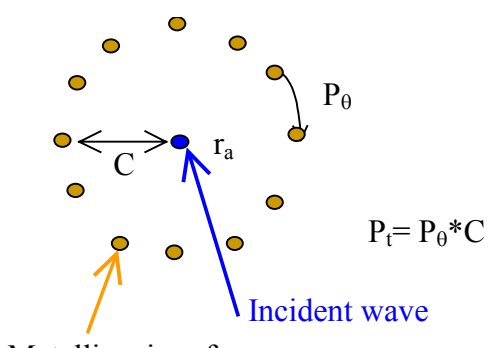

Metallic wire of

diameter a

(a)

Figure 1(a) Cylindrical periodic structure of metallic wires illuminated by an outgoing cylindrical incident wave

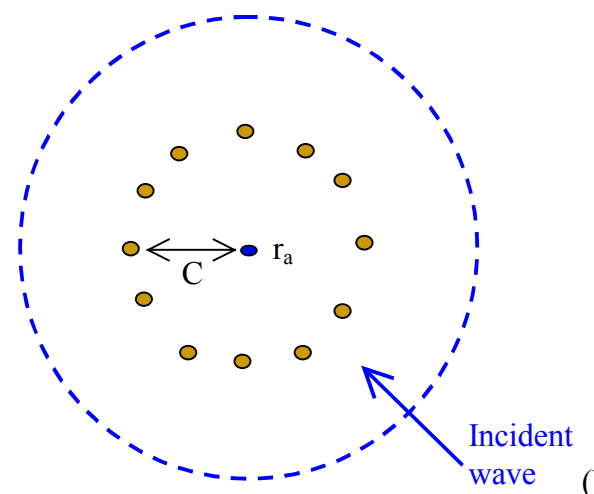

Figure 1 (b) Cylindrical periodic structure of metallic wires illuminated by an incoming cylindrical incident wave

Let us call $E(\rho)$ the tangential composing of the total electric field in function of the distance $\rho$ to the center The total field is the sum of the incident field and the diffracted field [1].

For case $1 a$ the expression of $\mathrm{E}$ is :

$$
E(\rho)=E_{\text {inc }}(\rho)+\sum_{n=1}^{N} K_{n} E_{d n}(\rho) \text { is : }
$$

For case $1 b$ the expression of $\mathrm{E}$ is :

$$
E(\rho)=E_{\text {inc }}(\rho)\left(1+r_{a} \exp \left(-2 j \eta_{0}(k \rho)\right)+\sum_{n=1}^{N} K_{n} E_{d n}(\rho)\right.
$$

Where $E_{\text {inc }}(\rho)=\mathrm{H}_{0}^{2}(\mathrm{k} \rho)$ for the outgoing cylindrical incident wave or $\mathrm{E}_{\text {inc }}(\rho)=\mathrm{H}_{0}^{1}(\mathrm{k} \rho)$ for the incoming cylindrical incident wave, $\eta_{0}(\mathrm{x})=\arctan \left(\frac{\mathrm{N}_{0}(\mathrm{x})}{\mathrm{J}_{0}(\mathrm{x})}\right), \mathrm{J}_{0}(\mathrm{x})$ and $\mathrm{N}_{0}(\mathrm{x})$ are the Bessel functions of order 0 , and $\mathbf{k}$ is the free space wave number. $\mathbf{r}_{\mathbf{a}}$ is the reflection coefficient in the center which is equal to one when no object is placed in the center. $E_{\mathrm{dn}}$ is the electric field diffracted by wire number $n(n=1, \ldots N) . K_{n}$ represent the unknown factors which contain the coupling between wires. Because of the symmetry theses factors don't depend on the wire considered :

$$
\sum_{n=1}^{N} K_{n} E_{d n}(\rho)=K \sum_{n=1}^{N} E_{d n}(\rho)
$$

$\mathrm{K}$ is determined by imposing zero to $\mathrm{E}$ at a surface of a metallic wire : 


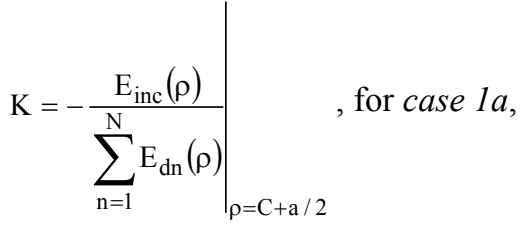

$$
\begin{aligned}
& \text { or } K=-\left.\frac{E_{\text {inc }}(\rho)\left(1+r_{a} \exp \left(-2 j \eta_{0}(k \rho)\right)\right.}{\sum_{n=1}^{N} E_{d n}(\rho)}\right|_{\rho=C+a / 2} \text {, for case } 1 b
\end{aligned}
$$

In fact, for all wires but one this condition will be took in the center of a wire and for this wire the condition is took at a distance $\mathrm{a} / 2$. For small diameter of wire a comparing to the wavelength, $\mathrm{E}_{\mathrm{dn}}$ are approximated by the Hankel function of first order $\mathrm{H}_{0}^{2}$. The formulation of $\mathrm{E}_{\mathrm{dn}}$ are given below :

$$
E_{d i}(\rho)=H_{0}^{2}\left(k \sqrt{C^{2}+\rho^{2}-2 C \rho \cos \left(\frac{(i-1) 2 \pi}{N}\right)}\right), i=1, \ldots N .
$$

The total field $\mathrm{E}(\rho)$ is then given by (1a) or (1b) for the two cases $l a$ and $l b$ respectively.

Let us call $\mathbf{T}$ the total transmission coefficient outside the cylindrical cavity and $\mathbf{R}$ the total reflection coefficient inside the cavity at a distance $\mathrm{D}(<\mathrm{C})$ from the center :

$$
\begin{gathered}
\mathrm{T}=\frac{\mathrm{E}(\rho)}{\mathrm{E}_{\text {inc }}(\rho)}, \rho>C+\mathrm{P}_{\mathrm{t}} \\
\mathrm{R}=\frac{\mathrm{E}(\rho)}{\mathrm{E}_{\text {inc }}(\rho)}, \rho=\mathrm{D}<\mathrm{C}-\mathrm{P}_{\mathrm{t}}
\end{gathered}
$$

We call $\mathbf{T}_{\mathbf{0}}$ the value of $\mathrm{T}$ when the incident wave $\mathrm{E}_{\text {inc }}$ is an outgoing wave (case la) and $\mathbf{T}_{\mathbf{i}}$ when it is an incoming wave (case 1 b). Similar definitions are given for $\mathbf{R}_{\mathbf{0}}$ and $\mathbf{R}_{\mathbf{i}}$.

\section{III- Characterization of a cylindrical periodic surface}

$(r, t)$ are the complex reflection and transmission coefficient of the cylindrical periodic structure of metallic wire for an outgoing cylindrical wave (figures 1a). ( $\mathrm{r}^{\prime}, \mathrm{t}^{\prime}$ ) are the complex reflection and transmission coefficient of the structure for an incoming cylindrical incident wave (figures $1 b$ ). The purpose of this part is to determine $(\mathrm{r}, \mathrm{t})$ and ( $\mathrm{r}^{\prime}, \mathrm{t}^{\prime}$ ) by the knowledge of $\mathbf{T}_{\mathbf{0}}, \mathbf{T}_{\mathbf{i}}, \mathbf{R}_{\mathbf{0}}$ and $\mathbf{R}_{\mathbf{i}}$. Let us insist that the method that we will describe can be used even if the total field is calculated by an another method that the method of part II. In [2,3] the problem of a source inside a cylindrical periodic surface have been also treated but the characteristics of the surface have not been given.

$\mathbf{T}_{\mathbf{0}}$ can be expressed in terms of $(\mathrm{r}, \mathrm{t})$ and $\mathrm{r}_{\mathrm{a}}$ (see figure 2a) :
$\mathrm{T}_{\mathrm{o}}=\mathrm{t} \sum_{\mathrm{n}=0}^{+\infty} \mathrm{r}^{\mathrm{n}} \mathrm{r}_{\mathrm{a}}{ }^{\mathrm{n}} \exp \left(-\mathrm{jn} 2 \eta_{0}(\mathrm{kC})\right)=\frac{\mathrm{t}}{1-\mathrm{rr}_{\mathrm{a}} \exp \left(-\mathrm{j} 2 \eta_{0}(\mathrm{kC})\right)}$

where $\eta_{0}(\mathrm{x})=\arctan \left(\frac{\mathrm{N}_{0}(\mathrm{x})}{\mathrm{J}_{0}(\mathrm{x})}\right)$

$\mathbf{R}_{\mathbf{0}}$ is the wave at a distance D from the line source inside the cavity, normalized by the incident wave (figure $2 b) . \mathbf{R}_{\mathbf{0}}$ can be expressed in terms of $(r, t)$ and $r_{a}$ :

$$
\mathrm{R}_{\mathrm{o}}=\frac{1+\mathrm{r} \cdot \exp \left(-\mathrm{j} 2 \eta_{0}(\mathrm{kC})+\mathrm{j} 2 \eta_{0}(\mathrm{kD})\right)}{1-\mathrm{rr}_{\mathrm{a}} \exp \left(-\mathrm{j} 2 \eta_{0}(\mathrm{kC})\right)}
$$

With expressions (7) and (8), we can calculate the reflection and transmission coefficients $(r, t)$ if we know $\mathrm{R}_{\mathrm{o}}$ and $\mathrm{T}_{\mathrm{o}}$ :

$$
r=\frac{R_{o}-1}{\left(r_{a} R_{o}+B_{D}^{*}\right) B_{C}}, \quad t=T_{o}\left(1-r_{a} B_{C}\right)
$$

where $B_{C}=\exp \left(-2 j \eta_{0}(k C)\right) \quad, \quad B_{D}^{*}=\exp \left(2 j \eta_{0}(k D)\right)$
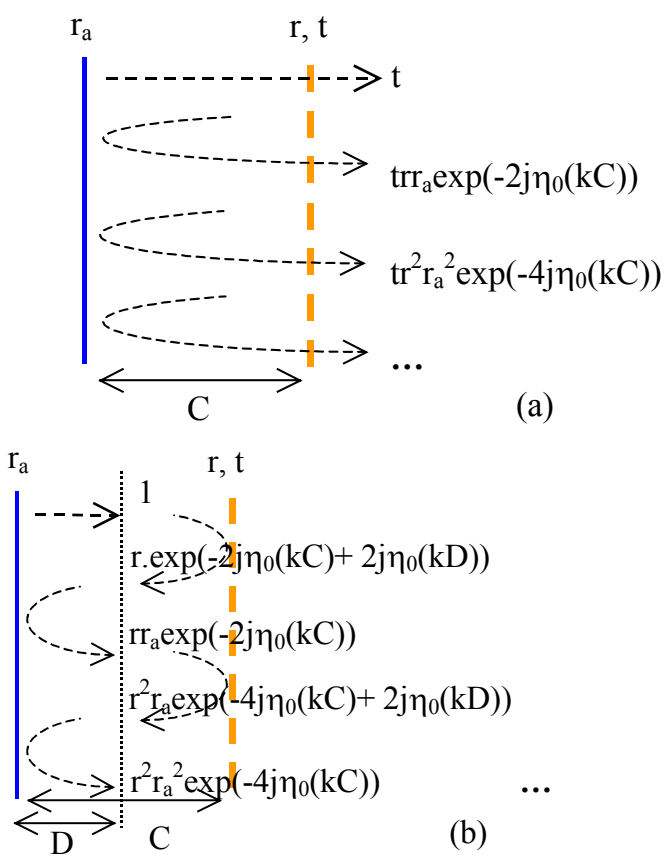

Figures $2:(a):$ Partial terms of the "total" transmission coefficient $\boldsymbol{T}_{\boldsymbol{o}}(b)$ : Partial terms of the "total" reflection coefficient $\boldsymbol{R}_{\boldsymbol{o}}$ inside the cavity

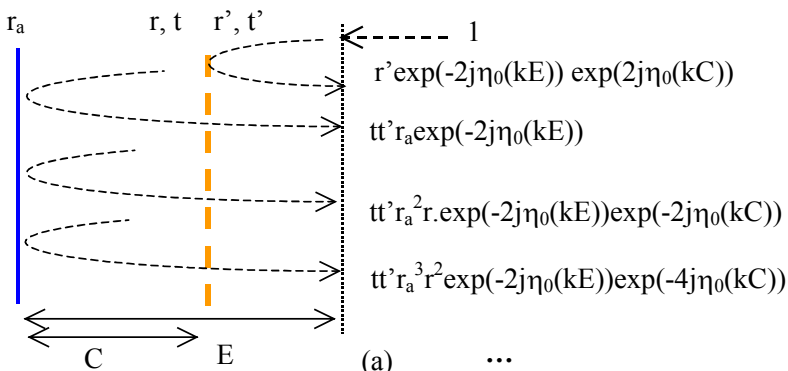




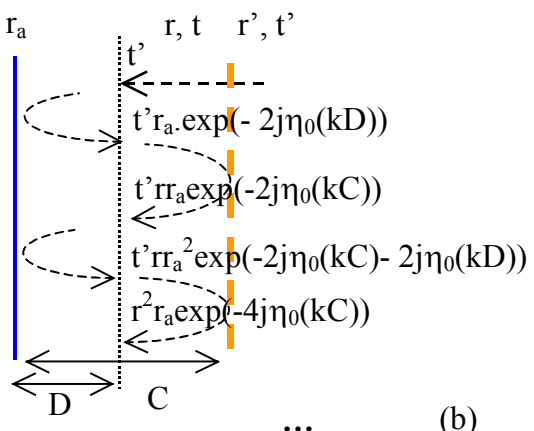

Figures $3:$ (a) : Partial terms of the "total" transmission coefficient $\boldsymbol{T}_{\boldsymbol{i}}($ b) : Partial terms of the "total" reflection coefficient $\boldsymbol{R}_{\boldsymbol{i}}$ inside the cavity

In figure $3 a$ we can see that $\mathbf{T}_{\mathbf{i}}$ can be expressed in terms of $\left(r^{\prime}, t^{\prime}\right),(r, t)$ and $\mathbf{r}_{\mathbf{a}}$ :

$$
\mathrm{T}_{\mathrm{i}}=1+\mathrm{r}^{\prime} \exp \left(-\mathrm{j} 2 \eta_{0}(\mathrm{kE})+\mathrm{j} 2 \eta_{0}(\mathrm{kC})\right)+\frac{\mathrm{t}^{\prime} \operatorname{tr}_{\mathrm{a}} \exp \left(-\mathrm{j} 2 \eta_{0}(\mathrm{kE})\right)}{1-\mathrm{rr}_{\mathrm{a}} \exp \left(-\mathrm{j} 2 \eta_{0}(\mathrm{kC})\right)}
$$
$3 a)$

$\mathbf{R}_{\mathbf{i}}$ can be expressed in terms of $\mathrm{t}^{\prime}, \mathrm{r}$ and $\mathrm{r}_{\mathrm{a}}$ (figure

$$
\mathrm{R}_{\mathrm{i}}=\frac{\mathrm{t}^{\mathrm{t}}\left(1+\mathrm{r}_{\mathrm{a}} \exp \left(-\mathrm{j} 2 \eta_{0}(\mathrm{kD})\right)\right)}{1-\mathrm{rr}_{\mathrm{a}} \exp \left(-\mathrm{j} 2 \eta_{0}(\mathrm{kC})\right)}
$$

With expressions (11) and (12), we can calculate the reflection and transmission coefficients $\left(r^{\prime}, t^{\prime}\right)$ if we know $\mathrm{R}_{\mathrm{i}}$ and $\mathrm{T}_{\mathrm{i}}$ and $(\mathrm{r}, \mathrm{t})$ :

$$
t^{\prime}=\frac{\left(1-r_{C}\right) R_{i}}{1+r_{a} B_{D}}, \quad r^{\prime}=\frac{1}{B_{E} B_{C}^{*}}\left(T_{i}-1-\frac{t^{\prime} r_{a} B_{E}}{1-r_{a} B_{C}}\right)
$$

where $\quad B_{C}=\exp \left(-2 \mathrm{j} \eta_{0}(k C)\right), \quad B_{E}=\exp \left(-2 j \eta_{0}(k E)\right)$,

$$
\mathrm{B}_{\mathrm{D}}=\exp \left(-2 \mathrm{j} \eta_{0}(\mathrm{kD})\right), \quad \mathrm{B}_{\mathrm{C}}^{*}=\exp \left(2 \mathrm{j} \eta_{0}(\mathrm{kC})\right)
$$

\section{IV- Radius periodic structures}

In Figure $4 a$ and Figure $4 b$, we plot the magnitudes of $(r, t)$ and $\left(r^{\prime}, t^{\prime}\right)$ and the phases of $r$ and r' obtained with $\mathrm{R}_{0}, \mathrm{~T}_{0}, \mathrm{R}_{\mathrm{i}}$ and $\mathrm{Ti}$ (obtained in part II) for two examples : $\mathrm{C}=40 \mathrm{~mm}$ and $\mathrm{C}=120 \mathrm{~mm}$ respectively, with $\mathrm{P}_{\mathrm{t}}$ constant. We see that (r', t') tend to $(\mathrm{r}, \mathrm{t})$ as $\mathrm{C}$ increase. In Figure 5 we can see that the resonances of $\mathrm{T}_{\mathrm{o}}$ are well given by the intersections of the phase of $\mathrm{r}$ and $2 \mathrm{k} \eta_{0}(\mathrm{kC})$. The condition of continuity $\mathrm{r}+1=\mathrm{t}$ have been verified also.

The value of $\left|\mathrm{T}_{\mathrm{o}}\right|$ superior to one (Figure 5) correspond to a matching of the ideal source $\left(\mathrm{r}_{\mathrm{a}}=1\right)$ and must not be took as a gain enhancement. We can note that an enhancement of the bandwidth of the resonance of $\left[T_{o} \mid\right.$ can be obtain if $\varphi_{\mathrm{r}}$ increase with frequency. This can be obtained with a negative index material as it is observed in $[5]$.
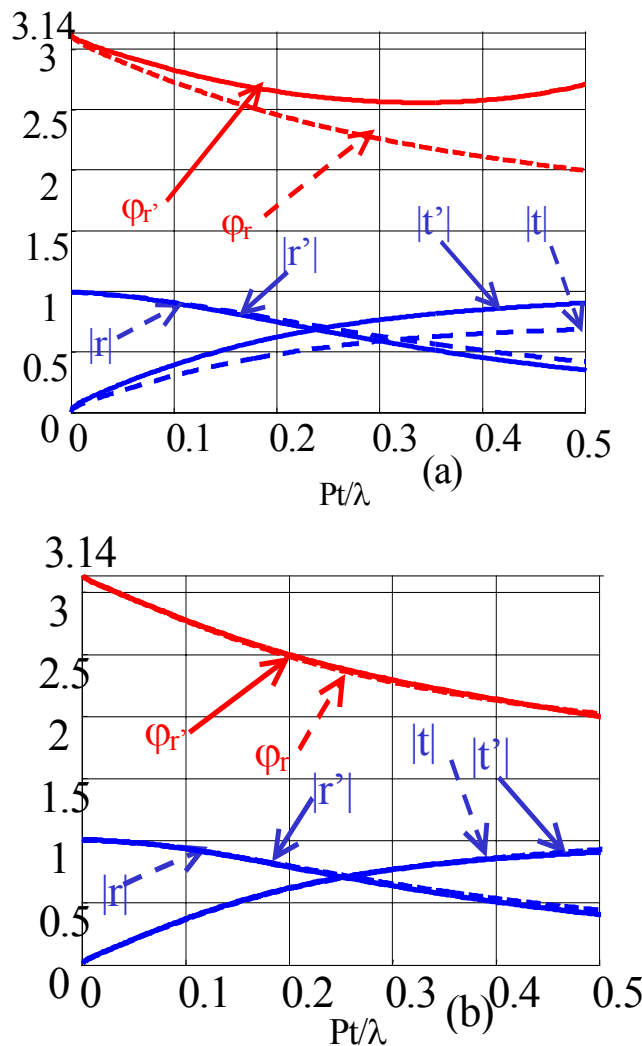

Figure $4:|t|,\left|t^{\prime}\right|,|r|,\left|r^{\prime}\right|, \varphi_{r}$ et $\varphi_{r^{\prime}}$ for (a) : $C=40 \mathrm{~mm}(b)$ : $C=120 \mathrm{~mm}(a, b) P t=p i / 6 * 40 \mathrm{~mm}$ constant

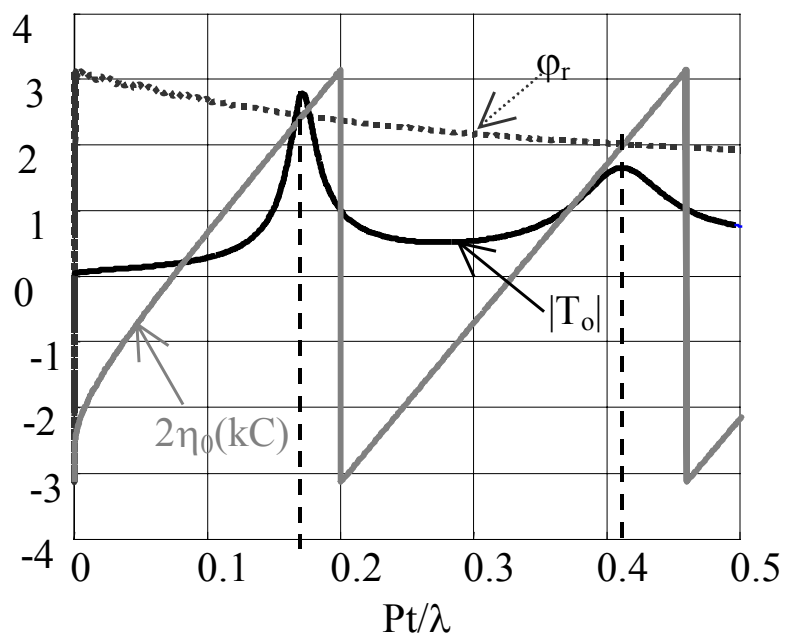

Figure 5: the resonances of $\left|T_{o}\right|$ correspond to the intersections between $\varphi_{r}$ and $2 \eta_{0}(\mathrm{kC})(\boldsymbol{C}=200 \mathrm{~mm}$, $\boldsymbol{a}=1 \mathrm{~mm}, \boldsymbol{P}_{\boldsymbol{\theta}}=30^{\circ}, \boldsymbol{P}_{\boldsymbol{t}}=\mathrm{pi} / 6^{*} 200 \mathrm{~mm} \approx 105 \mathrm{~mm}$ )

If we consider, now, two surfaces 1 and 2 (Figure 6), and if we consider only the reflections between these two surfaces (considering a matched source, i.e. $r_{a}=0$ ), then the transmission coefficient must be equal to :

$$
\mathrm{T}_{2}=\frac{\mathrm{t}_{1} \mathrm{t}_{2}}{1-\mathrm{r}_{1}{ }^{\prime} \mathrm{r}_{2} \exp \left(\mathrm{j} 2 \eta_{0}(\mathrm{kC})\right) \exp \left(-\mathrm{j} 2 \eta_{0}\left(\mathrm{k}\left(\mathrm{C}+\mathrm{P}_{\mathrm{r}}\right)\right)\right)}
$$

This is the cylindrical equivalent of the Fabry-Perot cavity in the plane case. 


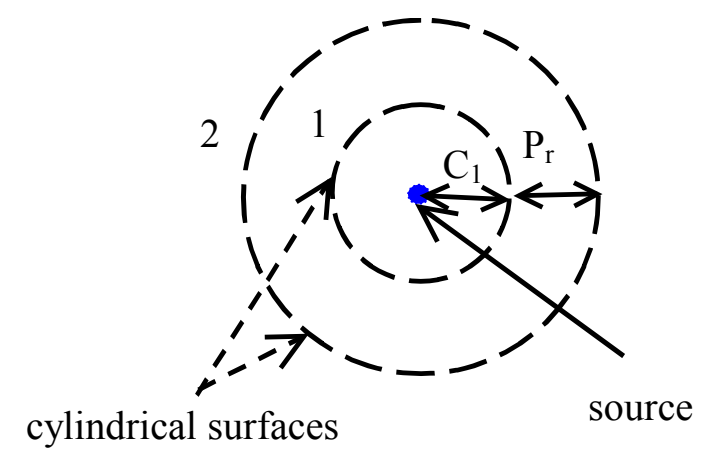

Figure 6: Two layer cylindrical periodic structure

$\left|\mathrm{T}_{2}\right|$

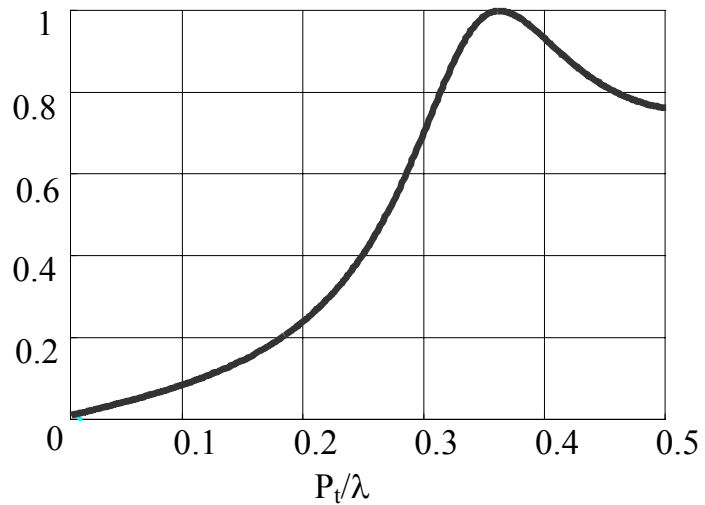

Figure 7 : Two layer cylindrical structure transmission coefficient $\left|\mathrm{T}_{2}\right|\left(\boldsymbol{a}=1 \mathrm{~mm} C_{1}=160 \mathrm{~mm}, \boldsymbol{P r}=40 \mathrm{~mm} \boldsymbol{P}_{\boldsymbol{\theta}}=15^{\circ}\right.$ $\boldsymbol{P}_{\theta 2}=12^{\circ}, \boldsymbol{P}_{\boldsymbol{t}}$ constant $)$

Figure 6 represent a cylindrical structure of two layers with a source in the center. Figure 7 give an example of the transmission coefficient of this structure if $\mathrm{r}_{\mathrm{a}}=0$.

The case of multiple surfaces is easy to obtain (by recurrence) and it is not necessary to develop it.

We consider, now, an infinite number of cylindrical surfaces. In the same way than in the plane case, we can consider that the cylindrical wave propagate in the structure with a constant of propagation $\beta$ (cylindrical Floquet equivalent theorem). We can see [4] also that the dispersion equation of the plane case is a good approximation of the dispersion equation :

$$
\cos \left(\beta \mathrm{P}_{\mathrm{r}}\right)=\cos \left(k \mathrm{P}_{\mathrm{r}}\right)+\mathrm{j} \frac{\mathrm{y}}{2} \sin \left(k \mathrm{P}_{\mathrm{r}}\right)
$$

Where $\mathrm{k}$ is the wave number, $\mathrm{P}_{\mathrm{r}}$ the radius period and $y=2(1-t) / t$ the normalized equivalent impedance of a cylindrical surface. The cylindrical surfaces have the same period $\mathrm{P}_{t}$ and then the same characteristics when $\mathrm{C}$ is sufficiently large.

Figure 8 represent a radius periodic cylindrical structure of multiple layers. Figure 9 give the modulus of $\mathrm{M}=\cos \left(\mathrm{kP}_{\mathrm{r}}\right)+\mathrm{jy} / 2 \sin \left(\mathrm{kP}_{\mathrm{r}}\right)(16), \beta \mathrm{P}_{\mathrm{r}}$ and also the magnitude of the reflection coefficient $\mathbf{r}_{6}$ of a six layer structure of metallic wires. A frequency band gap appears when $|\mathrm{M}|>1$ (no real solution for $\beta$ ) where $\left|r_{6}\right|$ is near 1 .

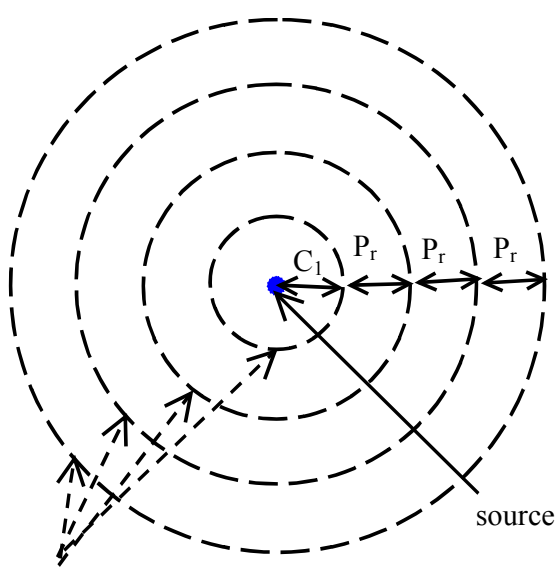

cylindrical surfaces

Figure 8 : Multiple layer cylindrical periodic structure

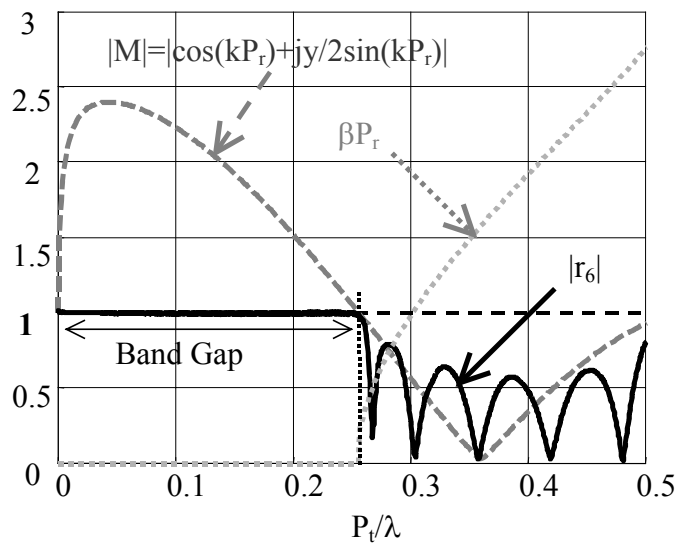

Figure 9 : Six layer cylindrical periodic structure reflection coefficient, $\beta P_{r}$ and $|M|(\boldsymbol{a}=1 \mathrm{~mm}$,

$\boldsymbol{P r}=\boldsymbol{C}_{\boldsymbol{1}}=40 \mathrm{~mm} \boldsymbol{P}_{\boldsymbol{\theta} \boldsymbol{i}}=60 \%$ i $(i=1,2, \ldots), \boldsymbol{P}_{\boldsymbol{t}}$ constant $)$

\section{V- Conclusion}

We have seen how to obtain the mains characteristics of a cylindrical periodic surface of metallic wires and of multiple layer radius periodic cylindrical structure. These methods will be used to design new types of antennas.

\section{References}

[1] R.F. Harington, Time Harmonic Electromagnetic Field, McGraw-Hill, New-York, 1961

[2] T. Cwick, Coupling into and scattering from cylindrical structures covered periodically with metallic patches, IEEE Trans. Antennas Propagat., Vol. 32, No. 2, Feb. 1990, pp. 220-226.

[3] Mokhtar, Analysis of Cylindrical Frequency Selective Surfaces, Fifteen National Radio Science Conference, Helwan, Cairo, Egypt, B81-B88, 1998

[4] H. Boutayeb, K. Mahdjoubi, A.C. Tarot, Radius Periodic Cylindrical Structures, APS/URSI International Symposium, Columbus, Ohio, USA, June 2003

[5] R. Ziolkowski, Artificial material that exhibit electromagnetic responses generally not found in nature, http://online.kitp.ucsb.edu/online/qo02/ziolkowski/, KITP, Santa Barbara, USA, December 2002 